\title{
SUSCETIBILIDADE À QUEDA NATURAL E CARACTERIZAÇÃO DOS FRUTOS DE DIVERSOS GENÓTIPOS DE BANANEIRAS ${ }^{1}$
}

\author{
MARLON CRISTIAN TOLEDO PEREIRA², LUIZ CARLOS CHAMHUM SALOMÃO ${ }^{3}$, SEBASTIÃO DE OLIVEIRA E \\ SILVA $^{4}$, PAULO ROBERTO CECON ${ }^{3}$, ROLF PUSCHMANN ${ }^{3}$, ONILDO NUNES DE JESUS ${ }^{5}$, \\ REGINALDO CONCEIÇÃO CERQUEIRA ${ }^{5}$
}

\begin{abstract}
RESUMO - A queda natural de frutos maduros da bananeira, resultado da separação individual de frutos da coroa da penca, também chamada despencamento, é uma característica indesejável, que pode limitar o lançamento de uma nova cultivar. O fruto destacado da penca tem vida de prateleira reduzida, além de não demonstrar boa aparência aos olhos do consumidor. Os objetivos do presente trabalho foram quantificar a suscetibilidade à queda natural dos frutos de bananeiras de grupos genômicos e ploidias diferentes, e identificar correlações entre a queda natural e diversas características físicas dos frutos. Foram utilizados 37 genótipos de bananeiras. De acordo com análise de variância e teste de Scott-Knott, os resultados evidenciaram a alta resistência ao despencamento dos genótipos pertencentes ao grupo genômico BB (Butuhan, Piraí e BB França), Terra (AAB), Poteau Nain (tipo figo) (ABB) e Thap Maeo (AAB), enquanto Prata-Anã (AAB), Grande Naine (AAA), Ambrósia (AAAA), Ouro (AA) e FHIA 18 (AAAB) obtiveram valores intermediários de resistência ao despencamento. Com relação às bananeiras suscetíveis, destacam-se os híbridos melhorados Pioneira (AAAB), YB42-21 (AAAB), Buccaneer (AAAA) e Calypso (AAAA) e a cultivar Ouro da Mata (AAAB). Verificou-se associação de $74 \%$ entre a firmeza do fruto e a resistência ao despencamento. Os estudos de grupos genômicos e ploidias indicaram maior resistência ao despencamento das bananeiras pertencentes ao grupo BB e dos genótipos triplóides ABB e AAB.
\end{abstract}

Termos para Idexação: Musa spp., híbridos, queda natural de frutos, caracterização de frutos.

\section{DIFFERENT BANANA GENOTYPES IN RELATION TO THEIR SUSCEPTIBILITY TO FINGER DROP AND FRUIT CHARACTERIZATION}

\begin{abstract}
Natural fruit dropping of ripe bananas in result of individual separation of fruits from the hand crown, is called finger drop, this characteristic is undesirable and would limit the marketing of new cultivars. Fruits that stand out in the hand have a reduced shelf life, and do not present a pleasant appearance for customers. This study was carried out in order to quantify the susceptibility to natural fruit dropping in fruits from different genomic groups and ploidies, and to identify correlations between natural dropping and various physical fruit characteristics. Diploid, triploid e tetraploid banana plants from several genomic groups were used, altogether 37 genotypes. The physical characteristics were used in a variance analysis and the results compared with the Scott-Knott test. Results proved the high resistance against dropping among genotypes that belong to the genomic group BB (Butuhan, Piraí and BB França), Terra (AAB), Poteau Nain (fig type) (ABB) and Thap Maeo (AAB), while Prata-Anã (AAB), Grande Naine (AAA), Ambrósia (AAAA), Ouro (AA) and FHIA 18 (AAAB) presented intermediate values of dropping resistance. Among banana plants with low resistence, the improved hybrids Pioneira (AAAB), YB42-21 (AAAB), Buccaneer (AAAA) and Calypso (AAAA) and the cultivar Ouro da Mata (AAAB) were outstanding. A higher positive correlation between fruit firmness and resistance toward finger drop could be verified. The study of genotype and ploid groups indicated a greater resistance against dropping among banana plants belonging to the BB group and $\mathrm{ABB}$ and $\mathrm{AAB}$ triploid genotypes.
\end{abstract}

Index Terms: Musa spp., hybrids, finger drop, fruit characterization.

\section{INTRODUÇÃO}

Um dos problemas para o lançamento de novas cultivares de bananeira tem sido a suscetibilidade dos frutos maduros à queda natural ("finger drop"), também chamada despencamento, queda dos dedos ou desprendimento dos frutos da coroa (Silva, 1999), implicando alta perecibilidade em pós-colheita.

A suscetibilidade à queda natural de frutos varia entre cultivares (Paull, 1996), tendo sido observada em triplóides do subgrupo Cavendish (AAA) (Hicks, 1934; Semple \& Thompson, 1988) e principalmente em tetraplóides, que normalmente apresentam maior suscetibilidade (Marriott, 1980). Vários híbridos tetraplóides lançados nos últimos anos pela Fundación Hondureña de Investigación Agrícola (FHIA), como FHIA 01, FHIA 02 e FHIA 18, com alta resistência à Sigatoka-negra e boas características agronômicas (Holderness et al., 2000), têm sua expansão limitada pela alta suscetibilidade à queda natural e pela alta perecibilidade pós-colheita de seus frutos. Por outro lado, cultivares como 'Terra' (AAB) apresentam excelente resistência à queda natural de frutos, mesmo estando esses maduros.

Os objetivos do presente trabalho foram quantificar a suscetibilidade à queda natural dos frutos de bananeiras de diversos genótipos, de grupos genômicos e ploidias diferentes; identificar correlações entre a queda natural e várias características físicas dos frutos, e obter subsídios para os estudos de melhoramento da bananeira.

\section{MATERIALEMÉTODOS}

O presente trabalho foi realizado na Embrapa Mandioca e Fruticultura, em Cruz das Almas-BA, no primeiro semestre de 2000. Foram utilizadas bananeiras diplóides, triplóides e tetraplóides do Banco Ativo de Germoplasma (BAG) (Tabela 1). Os cachos foram colhidos segundo critérios descritos por Alves (1999). Efetuou-se o despencamento dos cachos, selecionando-se a segunda, a terceira e a quarta pencas. Em galpão coberto, os frutos foram individualizados das pencas, selecionando-se 10 sem ferimentos e sem deformações. Os frutos foram lavados em água contendo $0,2 \%$ de detergente, em seguida imersos em solução de ethefon $\left(2.000 \mathrm{ml} \mathrm{L}^{-1}\right)$ durante cinco minutos. Estes foram acondicionados em caixas de papelão devidamente identificadas, após pesagem individual. Posteriormente, mediu-se comprimento do fruto, diâmetro da quina do fruto (calibração radial), diâmetro do fruto (calibração lateral), comprimento do pedicelo e diâmetro do pedicelo (Silva et al., 1999). A partir daí, as caixas de papelão contendo os frutos

\footnotetext{
${ }^{1}$ (Trabalho 040/2004). Recebido: 06/04/2004. Aceito para publicação: 24-09-2004 Parte da dissertação apresentada pelo primeiro autor, para obtenção do título de Doutor em Fitotecnia pela Universidade Federal de Viçosa (UFV). Apoio Financeiro: FAPEMIG.

${ }^{2}$ Eng $^{\circ}$ Agr ${ }^{\circ}$., Dr., Prof., Dep. Ciências Agrárias,UNIMONTES, Caixa Postal 91, CEP39440-000. Janaúba-MG. E-mail: marlonsilvia@ nortecnet.com.br.

${ }^{3}$ Eng $^{\circ}$ Agr $^{\circ}$., Dr., Prof., Dep. Fitotecnia, UFV, Bolsista do CNPq, CEP36571-000. Viçosa-MG. E-mail: 1salomao@ufv.br.

${ }^{4}$ Eng $^{\circ}$ Agr $^{\circ}$., Dr., Pesq. Embrapa Mandioca e Fruticultura, Caixa Postal 07, CEP 44380-000. Cruz das Almas-BA. E-mail: ssilva@ cnpmf.embrapa.br.

${ }^{5}$ Bolsistas da Embrapa Mandioca e Fruticultura.
} 
foram colocadas em câmara de armazenagem com ajuste da temperatura $\left(21 \pm 2^{\circ} \mathrm{C}\right)$ e umidade relativa $(95 \%)$.

Quando os frutos atingiram o estádio 6 de maturação (casca totalmente amarela), foram pesados individualmente e tiveram os valores de perda de matéria fresca expressos em percentagem do peso inicial (Dadzie \& Orchard,1997). Em seguida, efetuou-se o teste de resistência ao despencamento para quantificar o grau de suscetibilidade das cultivares à queda natural de frutos. A avaliação do despencamento foi feita utilizando o "Despencador Mecanizado" (Cerqueira, 2000). Mediram-se a firmeza $\left(\mathrm{N} / \mathrm{cm}^{2}\right)$ próximo às extremidades e no centro dos frutos (com casca) e a espessura da casca. Determinou-se a matéria seca da casca e da polpa, conforme metodologia de Dadzie \& Orchard (1997).

Foi utilizado o delineamento inteiramente casualizado, com 37 tratamentos (genótipos) e 10 repetições, sendo que, no caso específico de matéria seca da casca e da polpa, cada tratamento contou com cinco repetições.

Os valores obtidos foram submetidos à análise de variância e as médias foram comparadas pelo teste de Scott-Knott. Foi efetuado um estudo de correlação linear simples entre as características dos genótipos. Todas as análises estatísticas foram efetuadas com o auxílio do Sistema de Análises Estatísticas e Genéticas da Universidade Federal de Viçosa (SAEG-UFV).

\section{RESULTADOS E DISCUSSÃO}

Os frutos dos genótipos estudados apresentaram diferenças significativas em todas as características avaliadas. A resistência ao despencamento variou de 3,1 N a 101,2 N, em média, demonstrando a grande variabilidade entre as bananeiras estudadas (Tabela 1).

De acordo com os valores médios de despencamento dos frutos de bananeira obtidos pelo "Despencador Mecanizado" e com a experiência e os critérios práticos no Laboratório de Práticas Culturais da Embrapa Mandioca e Fruticultura, definiram-se os seguintes padrões de resistência ao despencamento: 1) Resistente $(>60 \mathrm{~N})$; 2) Medianamente Resistente (20-60 N), e 3) Suscetível (<20 N). Por meio do teste de médias de Scott-Knott, foi possível agrupar os valores médios mais semelhantes (Tabela 1).

Os frutos das bananeiras Terra, diplóides BB França, Butuhan e Piraí, Poteau Nain (tipo Figo) e Thap Maeo apresentaram maior resistência ao despencamento, enquanto Prata-Anã, Grande Naine, Ambrosia, Ouro e FHIA 18 obtiveram valores intermediários, considerados medianamente resistentes ao despencamento. Com relação às bananeiras suscetíveis, salienta-se a presença dos tetraplóides Pioneira, YB42-21, Buccanner, Calypso e Ouro da Mata, os quais podem ter problemas na comercialização dos frutos. Também surpreende a baixa resistência ao despencamento da

TABELA 1 - Grupo Genômico, genealogia, resistência ao despencamento (RDP) e firmeza do fruto (FIR) de 37 genótipos de bananeiras de diferentes ploidias ${ }^{1}$.

\begin{tabular}{|c|c|c|c|c|c|}
\hline Nome & Grupo Genômico & Genealogia & RDP $^{2}$ (Embrapa) & $\operatorname{RDP}^{3}(\mathbf{N})$ & $\operatorname{FIR}^{2}\left(\mathrm{~N} / \mathrm{cm}^{2}\right)$ \\
\hline BB França ${ }^{4}$ & $\mathrm{BB}$ & Diplóide silvestre & Resistente & $101,2 \mathrm{a}$ & $104,0 \mathrm{~b}$ \\
\hline Terra $^{4}$ & $\mathrm{AAB}$ & Cultivar & Resistente & $86,8 \mathrm{~b}$ & $149,1 \mathrm{a}$ \\
\hline Piraí $^{4}$ & $\mathrm{BB}$ & Diplóide silvestre & Resistente & $78,7 \mathrm{~b}$ & $99,8 \mathrm{~b}$ \\
\hline Butuhan $^{4}$ & $\mathrm{BB}$ & Diplóide silvestre & Resistente & $69,2 \mathrm{c}$ & $64,6 \mathrm{e}$ \\
\hline Poteau Nain ${ }^{4}$ & $\mathrm{ABB}$ & Cultivar & Resistente & $64,2 \mathrm{c}$ & $63,2 \mathrm{e}$ \\
\hline Thap Maeo & $\mathrm{AAB}$ & Cultivar & Resistente & $60,4 \mathrm{~d}$ & $58,5 \mathrm{f}$ \\
\hline Tjau Lagada & $\mathrm{AA}$ & Cultivar & Medianamente & $54,6 \mathrm{e}$ & $45,4 \mathrm{~h}$ \\
\hline ST42-08 & $\mathrm{AAAB}$ & Híbrido melhorado & Medianamente & $47,1 \mathrm{e}$ & $52,5 \mathrm{~g}$ \\
\hline Prata-Anã & $\mathrm{AAB}$ & Cultivar & Medianamente & $45,2 \mathrm{e}$ & $50,4 \mathrm{~g}$ \\
\hline PV42-85 & $\mathrm{AAAB}$ & Híbrido melhorado & Medianamente & $43,7 \mathrm{e}$ & $58,5 \mathrm{f}$ \\
\hline TH03-01 & AA & Híbrido melhorado & Medianamente & $42,1 \mathrm{e}$ & $87,4 \mathrm{c}$ \\
\hline Grande Naine & AAA & Cultivar & Medianamente & $38,3 \mathrm{f}$ & $68,6 \mathrm{~d}$ \\
\hline FHIA-01 & $\mathrm{AAAB}$ & Híbrido melhorado & Suscetível & $31,7 \mathrm{f}$ & $35,9 \mathrm{i}$ \\
\hline Pacovan & $\mathrm{AAB}$ & Cultivar & Medianamente & $29,7 \mathrm{f}$ & $39,1 \mathrm{i}$ \\
\hline PV03-44 & $\mathrm{AAAB}$ & Híbrido melhorado & Suscetível & $28,5 \mathrm{f}$ & $41,8 \mathrm{~h}$ \\
\hline Ambrósia & AAAA & Híbrido melhorado & Medianamente & $25,9 \mathrm{~g}$ & $48,4 \mathrm{~g}$ \\
\hline Ouro & $\mathrm{AA}$ & Cultivar & Medianamente & $24,7 \mathrm{~g}$ & $72,2 \mathrm{~d}$ \\
\hline FHIA-18 & $\mathrm{AAAB}$ & Híbrido melhorado & Suscetível & $23,2 \mathrm{~g}$ & $43,2 \mathrm{~h}$ \\
\hline Jary Buaya & $\mathrm{AA}$ & Cultivar & Medianamente & $21,2 \mathrm{~g}$ & $35,1 \mathrm{i}$ \\
\hline FHIA- $03^{4}$ & $\mathrm{AABB}$ & Híbrido melhorado & Resistente & $19,8 \mathrm{~g}$ & $26,8 \mathrm{k}$ \\
\hline Pioneira & $\mathrm{AAAB}$ & Híbrido melhorado & Suscetível & $18,2 \mathrm{~h}$ & $28,4 \mathrm{j}$ \\
\hline SH3263 & $\mathrm{AA}$ & Híbrido melhorado & Suscetível & $18,2 \mathrm{~h}$ & $51,8 \mathrm{~g}$ \\
\hline YB42-21 & $\mathrm{AAAB}$ & Híbrido melhorado & Medianamente & $16,7 \mathrm{~h}$ & $45,7 \mathrm{~h}$ \\
\hline Buccaneer & AAAA & Híbrido melhorado & Medianamente & $16,1 \mathrm{~h}$ & $42,7 \mathrm{~h}$ \\
\hline Calypso & AAAA & Híbrido melhorado & Medianamente & $15,6 \mathrm{~h}$ & $44,9 \mathrm{~h}$ \\
\hline $1741-01$ & AA & Híbrido melhorado & Suscetível & $15,0 \mathrm{~h}$ & $45,5 \mathrm{~h}$ \\
\hline SH3640 & AAAB & Híbrido melhorado & Medianamente & $14,4 \mathrm{~h}$ & $32,4 j$ \\
\hline $1304-04$ & $\mathrm{AA}$ & Híbrido melhorado & Suscetível & $13,4 \mathrm{~h}$ & $47,7 \mathrm{~g}$ \\
\hline Prata Comum & $\mathrm{AAB}$ & Cultivar & Medianamente & $12,5 \mathrm{~h}$ & $39,1 \mathrm{i}$ \\
\hline Calcutta & AA & Diplóide silvestre & Suscetível & $11,3 \mathrm{~h}$ & $47,5 \mathrm{~g}$ \\
\hline Tongat & $\mathrm{AA}$ & Cultivar & Medianamente & $9,0 \mathrm{i}$ & $38,7 \mathrm{i}$ \\
\hline M53 & $\mathrm{AA}$ & Híbrido melhorado & Suscetível & $7,5 \mathrm{i}$ & $48,2 \mathrm{~g}$ \\
\hline Ouro da Mata & $\mathrm{AAAB}$ & Cultivar & Suscetível & $6,6 \mathrm{i}$ & $20,7 \mathrm{k}$ \\
\hline Lidi & $\mathrm{AA}$ & Cultivar & Suscetível & $5,7 \mathrm{i}$ & $49,8 \mathrm{~g}$ \\
\hline 2803-01 & $\mathrm{AA}$ & Híbrido melhorado & Resistente & $4,6 \mathrm{i}$ & $24,2 \mathrm{k}$ \\
\hline Tuugia & $\mathrm{AA}$ & Cultivar & Medianamente & $4,1 \mathrm{i}$ & $29,6 j$ \\
\hline Caipira & AAA & Cultivar & Medianamente & $3,1 \mathrm{i}$ & 9,91 \\
\hline $\mathrm{CV}(\%)$ & - & - & - & 31,5 & 12,0 \\
\hline
\end{tabular}

'Médias seguidas da mesma letra, em cada coluna, não diferem estatisticamente entre si, pelo teste de Scott-Knott, a 5\% de probabilidade.

${ }^{2}$ Método prático usado no laboratório de Pós-colheita da Embrapa Mandioca e Fruticultura, baseado na observação dos funcionários

${ }^{3}$ Frutos no estádio 6 de maturação ou totalmente amarelos

${ }^{4}$ Plátano, ou seja, genótipos com frutos consumidos fritos ou cozidos 
'Prata Comum', que é das cultivares mais plantadas no Brasil. Talvez a concentração de ethefon uniformizada em $2000 \mathrm{ml} . \mathrm{L}^{-1}$, indicada principalmente para os frutos do subgrupo Cavendish, utilizada em todos os genótipos, tenha provocado este comportamento na 'Prata Comum', que com $400 \mathrm{ml} . \mathrm{L}^{-1}$ já seria suficiente para o amadurecimento. Caipira mostrou-se a mais suscetível entre as bananeiras avaliadas, o que também é indesejável, já que essa variedade vem sendo recomendada para a região Norte do Brasil, devido à sua resistência à Sigatoka-negra (Pereira et al., 2000). Os resultados obtidos para 'Prata Comum' e Caipira divergem da classificação arbitrária descrita na Tabela 1, onde foram descritas como medianamente resistentes ao despencamento. Pereira \& Gasparotto (2001) também relatam que Caipira apresenta alta resistência ao despencamento. Tal discrepância pode estar relacionada ao estádio de maturação em que as análises foram realizadas, pois quanto mais maduro o fruto, mais facilmente ocorre o despencamento. Por serem os materiais avaliados distintos geneticamente, torna-se difícil a perfeita uniformização, por critérios visuais, do ponto de análise.

As cultivares Prata-Anã e Pacovan, predominantes no Vale do São Francisco, respectivamente com $62 \%$ e $27 \%$ da área plantada (Item, 2001), apresentaram-se medianamente resistentes ao despencamento, porém, devido à suscetibilidade à Sigatoka-negra, podem ter suas áreas de plantio reduzidas com a provável introdução desta doença.

Por meio da média das características dos frutos de cada grupo genômico, efetuou-se a análise de variância e testes de média, onde todas as características apresentaram diferenças significativas, ao nível de $5 \%$ de probabilidade.

Os frutos das bananeiras pertencentes ao grupo genômico BB apresentaram maior resistência ao despencamento, seguido por $\mathrm{ABB}$, com valores médios de $83,1 \mathrm{~N}$ e 64,2 N, respectivamente, enquanto o grupo $\mathrm{AAB}$ foi considerado medianamente resistente, com 46,9 N. Os outros grupos genômicos não diferiram estatisticamente entre si, porém apresentaram valores inferiores aos já citados, variando de 17,8 $\mathrm{N}$ a 25,6 $\mathrm{N}$ (Tabela 2). Este comportamento indica que a presença do genoma $\mathrm{B}$ (M. balbisiana) propicia maior resistência ao despencamento dos frutos, ao contrário da presença do genoma $\mathrm{A}(M$. acuminata $)$. Isto pode ser um indicativo de que os genes de resistência ao despencamento podem estar associados à espécie $M$. balbisiana.

As formas selvagens da espécie $M$. balbisiana apresentam pouca variabilidade genética e poucas características agronômicas desejáveis. Ao contrário, a variabilidade genética importante da bananeira localiza-se nas diversas formas selvagens da espécie $M$. acuminata e nas cultivares do grupo AA (Silva, 2000).

O grupo genômico AA apresentou o menor valor de resistência ao despencamento. Entretanto, é importante ressaltar que, dentre os genótipos AA, existem alguns que apresentam resistência mediana ao despencamento, a exemplo da Tjau Lagada e TH03-01, com resistência de 54,6 N e 42,1 N, respectivamente (Tabela 1). Portanto, o melhoramento de bananeira com o uso de diplóides AA, embora deixe de aproveitar genótipos de maior resistência ao despencamento, como os BB, pode buscar essa característica na Tjau Lagada e/ou no híbrido TH03-01 (Silva, 2000).

Na prática, verifica-se a grande utilização de diplóides AA melhorados como um dos principais caminhos para o desenvolvimento de novos híbridos mais resistentes ao despencamento. Por outro lado, os diplóides AA Tuugia, 2803-01, Lidi, M 53, Tongat, Calcutta, 1304-04 e 1741-01, largamente usados no programa de melhoramento da bananeira, realizado pela Embrapa Mandioca e Fruticultura, devido a suas características agronômicas, apresentaram-se bastante suscetíveis ao despencamento, com valores inferiores à Pioneira, a qual é considerada de muito fácil despencamento.

$\mathrm{O}$ grupo genômico $\mathrm{AABB}$, representado apenas pelo híbrido FHIA 03, não seguiu o comportamento dos grupos que possuem BB, o que talvez possa ser explicado pelo fato de ser um tetraplóide, portanto, apresentando maior facilidade para despencar do que as bananeiras pertencentes às demais ploidias (Marriot, 1980).

As bananeiras foram agrupadas com relação à sua ploidia e resistência ao despencamento. Os dados foram submetidos à análise de variância e teste de média. Observou-se diferença significativa entre os grupos, ao nível de $1 \%$ de probabilidade. Este novo agrupamento permitiu visualizar que, entre os diplóides e triplóides, existe uma ampla variabilidade para resistência ao despencamento, com valores variando em média de 7,8 N (triplóide suscetível) a 83,1 N (diplóide resistente) (Tabela 3). Por outro lado, os tetraplóides apresentaram menor amplitude de médias, oscilando de 15,4 N (tetraplóides suscetíveis) a 33,4 N (tetraplóides medianamente resistentes), lembrando que não houve nenhum tetraplóide classificado como resistente ao despencamento.

Este fato é preocupante, já que a obtenção de híbridos tetraplóides resistentes a doenças (um dos principais alvos dos programas de melhoramento de bananeiras) tem sido um dos caminhos mais curtos e fáceis para obtenção de novas cultivares de bananeiras. No entanto, há uma resistência grande dos produtores na utilização de novos materiais para plantio. Mais difícil será a aceitação de uma nova cultivar de banana que apresente fácil despencamento após amadurecimento. Entretanto, deve-se salientar que a Sigatoka-negra, presente em toda a região Norte do Brasil e no Mato Grosso (Pereira et al., 2000), está se aproximando das regiões de grande produção do Sudeste, e sua presença praticamente inviabiliza o cultivo das cultivares tradicionalmente em uso, que são suscetíveis à doença, sem o emprego maciço de fungicidas. $\mathrm{O}$ uso de híbridos resistentes à Sigatoka-negra apresenta-se como alternativa barata e ecologicamente correta. Se tais híbridos possuem problemas em pós-colheita, justificam-se estudos no manejo de modo a contornar estes distúrbios.

Apesar de não ter sido detectado tetraplóide resistente, observou-se que os tetraplóides ST42-08 (47,1 N) e PV42-85 (43,7 N) apresentaram resistência mediana ao despencamento, inclusive não diferindo significativamente da cultivar Prata-Anã (45,2 N), amplamente plantada e sem problemas de queda natural dos frutos. Resultados semelhantes foram relatados por Cerqueira (2000), obtendo valores de 49,6 N para ST42-08 e 49,0 N para PV42-85. Segundo este autor, estes tetraplóides apresentaram valores de resistência ao despencamento superiores aos triplóides que lhes deram origem, a Prata São Tomé (15,7 N) e a Pacovan $(47,8 \mathrm{~N})$, respectivamente. É importante salientar que, no presente trabalho, o diplóide parental dos híbridos referidos, M-53, considerado suscetível com 7,5 N (Tabela 1), auxilia na contradição da afirmativa de que a tendência da resistência ao despencamento possa ser herdada ou transferida aos novos híbridos (Dadzie \& Ochard, 1997). Neste momento, justifica-se a necessidade de um estudo mais aprofundado da herança da resistência ao despencamento, podendo facilitar o

TABELA 2 - Resistência ao despencamento (RDP) de genótipos de bananeira agrupados segundo os grupos genômicos

\begin{tabular}{lcccccccc}
\hline Grupos Genômicos & AA & AAA & AAAA & AAB & AAAB & AABB & ABB & BB \\
\hline RDP $(\mathrm{N})$ & $17,8 \mathrm{~d}$ & $20,7 \mathrm{~d}$ & $19,2 \mathrm{~d}$ & $46,9 \mathrm{c}$ & $25,6 \mathrm{~d}$ & $19,8 \mathrm{~d}$ & $64,2 \mathrm{~b}$ & $83,1 \mathrm{a}$ \\
\hline
\end{tabular}

Médias seguidas da mesma letra não diferem estatisticamente entre si, pelo teste de Scott-Knott, a 5\% de probabilidade. CV: 17,6\%.

TABELA 3 - Resistência ao despencamento (RDP) de genótipos diplóides, triplóides e tetraplóides de bananeiras

\begin{tabular}{lcccccccc}
\hline Ploidia & Diplóide S & Diplóide MR & Diplóide R & Triplóide S & Triplóide MR & Triplóide R & Tetraplóide S & Tetraplóide MR \\
\hline RDP $(\mathrm{N})$ & $9,9 \mathrm{e}$ & $35,7 \mathrm{c}$ & $83,1 \mathrm{a}$ & $7,8 \mathrm{e}$ & $37,8 \mathrm{c}$ & $70,5 \mathrm{~b}$ & $15,4 \mathrm{~d}$ & $33,4 \mathrm{c}$ \\
\hline
\end{tabular}

$\mathrm{S}=$ suscetível; $\mathrm{MR}=$ medianamente resistente; $\mathrm{R}=$ resistente ao despencamento

Médias seguidas da mesma letra não diferem estatisticamente entre si, pelo teste de Scott-Knott, a 5\% de probabilidade. CV: 17,5\%. 
aproveitamento desta característica na incorporação aos novos materiais.

De acordo com Cruz \& Regazzi (1997), o conhecimento da associação entre caracteres é de grande importância nos trabalhos de melhoramento, principalmente se a seleção em um deles apresenta dificuldades, em razão dos procedimentos de medição e/ou da baixa herdabilidade. Por meio da análise de correlação, verificou-se que a firmeza apresentou um grau de associação de $74 \%$ com a resistência ao despencamento (Tabela 4), significando que os frutos que são suscetíveis ao despencamento normalmente apresentam baixa firmeza e vice-versa. Uma substancial perda de firmeza ocorre em muitos frutos durante o amadurecimento. $\mathrm{O}$ amaciamento que ocorre é primariamente devido à mudança no metabolismo dos carboidratos componentes da parede celular ou seja, celulose, hemicelulose e pectina (Pressey \& Avants, 1982). Acreditase que a pectinametilesterase tem pouco efeito no amaciamento, servindo apenas para causar parcial desmetilação e permitindo a atividade da poligalacturonase. Esta desesterificação ocorre, com a perda de ramificações laterais de galactose e arabinose das pectinas, durante o amadurecimento do fruto (Paul \& Chen, 1983). O amaciamento que se observa nesta fase, corresponde à redução do conteúdo de pectina.

A porcentagem de perda de água não apresentou associação com a resistência ao despencamento, diferente dos resultados observados por Paul (1996) e Semple \& Thompson (1988), os quais detectaram que a redução da queda natural de frutos de bananeira está associada à maior perda de água e mais rápido amadurecimento em bananeira. Assim, esses autores concluíram que frutos que perdem muita água durante o amadurecimento, são mais resistentes à queda natural.

As demais características apresentaram baixos graus de associação com a resistência ao despencamento.

TABELA 4 - Coeficientes de correlações fenotípicas entre treze caracteres ${ }^{1}$, avaliados em 37 genótipos de bananeira

\begin{tabular}{|c|c|c|c|c|c|c|c|c|c|c|c|c|c|}
\hline Caracteres & RDP & FIR & CFR & CPD & PPA & TMA & PFR & MSC & MSP & DPD & DQN & DFR & ESC \\
\hline RDP & 1,00 & 0,74 & 0,03 & 0,47 & 0,00 & $-0,03$ & 0,28 & 0,11 & 0,46 & 0,01 & 0,39 & 0,36 & 0,16 \\
\hline FIR & & 1,00 & 0,05 & 0,40 & $-0,04$ & $-0,04$ & 0,22 & 0,10 & 0,54 & $-0,04$ & 0,21 & 0,19 & 0,03 \\
\hline CFR & & & 1,00 & 0,49 & $-0,44$ & $-0,35$ & 0,82 & $-0,57$ & $-0,41$ & 0,58 & 0,61 & 0,58 & 0,65 \\
\hline CPD & & & & 1,00 & 0,01 & $-0,08$ & 0,61 & $-0,09$ & 0,06 & 0,30 & 0,53 & 0,51 & 0,21 \\
\hline PPA & & & & & 1,00 & 0,77 & $-0,49$ & 0,61 & 0,01 & $-0,30$ & $-0,52$ & $-0,52$ & $-0,52$ \\
\hline TMA & & & & & & 1,00 & $-0,45$ & 0,56 & $-0,17$ & $-0,31$ & $-0,40$ & $-0,41$ &,- 055 \\
\hline PFR & & & & & & & 1,00 & $-0,55$ & $-0,17$ & 0,64 & 0,88 & 0,89 & 0,70 \\
\hline MSC & & & & & & & & 1,00 & 0,29 & $-0,52$ & $-0,41$ & $-0,40$ & $-0,71$ \\
\hline MSP & & & & & & & & & 1,00 & $-0,35$ & $-0,06$ & $-0,10$ & $-0,17$ \\
\hline DPD & & & & & & & & & & 1,00 & 0,49 & 0,55 & 0,55 \\
\hline DQN & & & & & & & & & & & 1,00 & 0,96 & 0,60 \\
\hline DFR & & & & & & & & & & & & 1,00 & 0,58 \\
\hline ESC & & & & & & & & & & & & & 1,00 \\
\hline
\end{tabular}

${ }^{1}$ RDP: resistência ao despencamento; FIR: firmeza do fruto; CFR: comprimento do fruto; CPD: comprimento do pedicelo; PPA: porcentagem de perda de água do fruto; TMA: tempo de maturação do fruto; PFR: peso do fruto; MSC: matéria seca da casca; MSP: matéria seca da polpa; DPD: diâmetro do pedicelo do fruto; DQN: diâmetro do fruto medido nas quinas; DFR: diâmetro do fruto; ESC: espessura da casca.

\section{CONCLUSÕES}

A resistência ao despencamento parece estar associada à presença do genoma B, embora exista variabilidade para a característica dentro do genoma A. Os híbridos tetraplóides melhorados Pioneira (AAAB), YB42-21 (AAAB), Buccaneer (AAAA) e Calypso (AAAA) e a cultivar Ouro da Mata (AAAB) demonstram suscetibilidade ao despencamento. A firmeza do fruto está associada em $74 \%$ com a resistência ao despencamento.

\section{REFERÊNCIAS}

ALVES, E. J. A cultura da banana: aspectos técnicos, socioeconômicos e agroindustriais. 2. ed. Brasília: Embrapa-SPI/Cruz das Almas: EmbrapaCNPMF, 1999. 585p.

CERQUEIRA, R. C. Avaliação de características pós-colheita de genótipos de bananeira (Musa spp.). Cruz das Almas, BA: UFBA, 2000. 60f. Dissertação, (Mestrado em Ciências Agrárias) - Universidade Federal da Bahia, Cruz das Almas, 2000.

CRUZ, C. D.; REGAZZI, A. J. Modelos biométricos aplicados ao melhoramento genético. Viçosa: UFV, 1997.390p.

DADZIE, B. K.; ORCHARD, J. E. Evaluación rutinaria postcosecha de híbridos de bananos y plátanos: criterios y métodos. IPGRI: Roma, INIBAP: Montpelier, 1997. 63p. (Guias técnicas Inibap, 2)

HICKS, E. W. Finger dropping from bunches of Australian Cavendish Bananas. Journal of Council Science Ind. Research., v.7, p.165-168, 1934.

HOLDERNESS, M.; SHARROCK, S.; FRISON, E.; KAIRO, M. (Ed.). Organic banana 2000: towards an organic banana initiative in the Caribbean. Report of the International workshop on the production and marketing of organic bananas by smallholder farmers. Montpellier: INIBAP, 2000. 174p.
ITEM. Irrigação e tecnologia moderna. Brasília: ABID, n.49, 2001. 83p.

MARRIOTT, J. Bananas: physiology and biochemistry of storage and ripening for optimum quality. Critical Reviews in Food Science and Nutrition, Boca Raton, v.13, p.41-88, 1980.

PAULL, R. E. Ethylene, storage and ripening temperatures affect Dwarf Brasilian banana finger drop. Postharvest Biology and Technology, v.8, p.64-74, 1996

PAUL, R. E.; CHEN, N. J. Postharvest variation in cell wall - degradation enzymes of papaya (Carica papaya L.) during fruit ripening. Plant Physiology, Washington, v.72 p.382-385, 1983.

PEREIRA, J. C. R.; GASPAROTTO, L.; COELHO, A. F.; VÉRAS, S. M. Doenças da bananeira no estado doAmazonas. 2. ed. Manaus: Embrapa Amazônia Ocidental, 2000.27 p. (Circular técnica, 7).

PEREIRA, J. C. R.; GASPAROTTO, L. Sigatoka-negra da bananeira. In: SIMPÓSIONORTEMINEIRO SOBREACULTURADABANANA, 1 , 2001, Nova Porteirinha, MG Anais...p.102-104.

PRESSEY, R.; AVANTS, J. K. Solubilization of cell walls by tomato polygalacturonases: effects of pectinesterases. Journal of Food Biochemistry, Westport, v.6, n.1 p. 57-74, 1982.

SEMPLE, A. J.; THOMPSON, A. K. Influence of the ripening environment on the development of finger drop in bananas. Journal of the Science Food and Agriculture, Chichester, v.46, p.139-146, 1988.

SILVA, C. L. Aplicação pós-colheita de cálcio em frutos de bananeira (Musa sp.) cultivar Pioneira. 1999. 56f. Dissertação (Mestrado em Ciências Agrárias) - Universidade Federal da Bahia, Cruz das Almas, 1999.

SILVA, S. O.; CARVALHO, P. C. L.; SHEPHERD, K.; ALVES, E. J.; OLIVEIRA, C.A.P.; CARVALHO, J.A. B.S. Catálogo de germoplasma de bananeira (Musa spp.). Cruz das Almas-BA: Embrapa Mandioca e Fruticultura, 1999. 52p. (Documentos, 20).

SILVA, S. O. Melhoramento genético da bananeira. In: SIMPÓSIO BRASILEIRO DE MELHORAMENTO DE FRUTEIRAS, 2, 2000, Viçosa-MG. Anais... p.21-48. 